\title{
Dual Morphology (Fibres And Particles) Cellulosic Filler For WPC Materials
}

\author{
Marco Valente ${ }^{\mathrm{a}}$, Jacopo Tirillò ${ }^{\mathrm{b}}$, Alessia Quitadamo ${ }^{\mathrm{c}}$, Carlo Santulli ${ }^{\mathrm{d}}$ \\ ${ }^{a, b, c}$ University of Rome La Sapienza Dep. of Chemical and Material Engineering \\ ${ }^{d}$ University of Camerino, School of Architecture and Design \\ marco.valente@uniroma1.it, calessia.quitadamo@uniroma1.it
}

\begin{abstract}
Wood-plastic composites (WPC) were fabricated by using a polyethylene (PE) matrix and filling it with wood flour in the amount of $30 \mathrm{wt} . \%$, and compared with the same composites with further amount of $10 \mathrm{wt} . \%$ of cellulosic recycled fibres added. The materials were produced by turbomixing and subsequent moulding under pressure. Mechanical properties of both WPC and WPC with cellulosic recycled fibres were evaluated through mechanical and physical-chemical tests. Tensile tests clarified that a moderate reduction is strength is observed with the bare introduction of wood flour with respect to the neat PE matrix, whilst some recovery is offered by the addition of recycled cellulose fibres. Even more promisingly, the elastic modulus of PE matrix is substantially improved by the addition of wood flour (around $8 \%$ on average) and much more so with the further addition of recycled cellulose (around $20 \%$ on average). The fracture surfaces from the tensile test were analysed by scanning electron microscope (SEM) indicating a reduction in microporosity as an effect of added cellulose. The water absorption test and the hardness measure (Shore D) were also performed. SEM analysis underlined the weak interface between both wood particle and cellulosic recycled fibres and matrix. The water absorption test showed a higher mass variation for pure WPC than WPC with cellulosic recycled fibres. The hardness measurement showed that the presence of cellulosic recycled fibres improves both superficial hardness of the composite and temperature resistance.
\end{abstract}

Keywords: WPC, Thermoplastic composites, cellulosic fibres materials, paper recycling PACS: $81.05 . \mathrm{Lg}$

\section{INTRODUCTION}

Wood-plastic composites (WPC) are produced with wood flour, which is the dispersed phase, and polymeric matrix, generally polyethylene, polypropylene or other thermoplastic polymers [1]. They underwent a significant yet rapid development during last years thanks to the possibility of reducing the environmental impact by their production [2]: oil-based conventional plastic is in fact a major contributor to pollution because it constitutes a large portion of total waste and its non-biodegradability, whereas the use of virgin wood is responsible of huge deforestation and consumption of trees and generally its wastes are burned or dumped. The application of wood waste and polymer for the production of these composites, allows reducing the amount of waste and preserve nature. Moreover costs, energy and the use of virgin materials are also reduced [3]. Because of that, WPCs are an interesting class of materials in order to reduce the environmental impact and they are moreover characterized by positive properties like low prices, resistance to biological deterioration, ease of modeling and ability to use the same methods of traditional woodworking [4]. However, because of the hydrophilic nature of wood and the hydrophobic one for the matrix, these composites are characterized by reduced mechanical properties due to a weak interface [5]. An improvement of WPC properties is possible through the cellulosic fibres introduction. In order to preserve the environmental friendly properties, the cellulosic fibres are obtained from paper waste. In this work we investigated the properties of WPC with high-density polyethylene as continuous phase, wood flour and cellulosic recycled fibres as dispersed one. The effect of cellulosic fibres introduction is analysed through the tensile test, the SEM analysis of the fracture surfaces, the water absorption and superficial hardness.

\section{MATERIALS AND METHODS}

The composites are produced through turbomixing and then moulded under a pressure of 10 bars, obtaining plates from which specimens were removed. The detail production process was analysed in our previous work [6].

\section{Materials}

Eraclene MP90, the commercial name of a high density polyethylene (HDPE), has been chosen as matrix from General Electrics (GE). Its properties are a Melt Flow Index (MFI) of $7.0 \mathrm{~g} / 10 \mathrm{~min}\left(190^{\circ} \mathrm{C} / 2.16 \mathrm{~kg}\right)$, a density of $0.96 \mathrm{~g} / \mathrm{cm}^{3}$, a tensile strength of $20 \mathrm{MPa}$, a flexural modulus of $1.25 \mathrm{GPa}$, and Shore D hardness of 50 . Wood flour of hardwood beech was provided by La.So.Le Est Srl-Italy. The wood particles have diameters ranging between 500 and $250 \mu \mathrm{m}$. 
Cellulosic recycled paper was derived from a common industrial product and used as self-adhesive labels. This kind of paper is a special waste, deriving from a previous study in which was also involved CARLUCCI company (Pomezia, nr. Rome, in Italy). The proposal is to use this waste as filler in WPCs, reducing the environmental impact and improving WPC properties. In order to obtain paper suitable for incorporation in polymeric matrix, micronization treatment is needed through a mill that exploits simultaneously the action of impact, shear and turbulence. With this process it was possible to obtain fibres with diameters of about 15-20 microns and lengths in the order of 250-500 microns.

Samples with HDPE matrix and $30 \mathrm{wt} \%$ of wood flour (referred to as 30W) and with HDPE matrix and $30 \mathrm{wt} \%$ of wood flour and $10 \mathrm{wt} \%$ of cellulosic recycled fibres (referred to as $30 \mathrm{~W} 10 \mathrm{~F}$ ) were produced and tested. The latter percentages have been chosen because they are close to $1 / 1 / 1$ volume percentage (HDPE/wood/fibres).

\section{Methods}

\section{Tensile tests}

The tests were conducted in accordance with ASTM D 3039-14 standard using a Zwick/Roell Z010: a 50N preload was applied. The specimens, obtained from 100mmx200mmx2 mm (LxWxT) plates, have dimensions of 200x12.5x2 $\mathrm{mm}$ (LxWxT). The crosshead speed was $5 \mathrm{~mm} / \mathrm{min}$. Each category of samples is composed of five specimens.

\section{Scanning Electron Microscopy}

The specimens were observed with SEM (Philips XL40) to analyse the fibres and particles dispersion in the matrix and the interface quality. The samples were sputter-coated with gold particles before the surface characterization.

\section{Water Absorption Tests}

The water absorption tests were performed in accordance with ASTM D570-98(2010). The specimens were oven dried at $105^{\circ} \mathrm{C}$ for 24 hours and then immersed in water until saturation has been reached at room temperature $\left(21^{\circ} \mathrm{C}\right), 40^{\circ} \mathrm{C}$ and $60^{\circ} \mathrm{C}$. For each temperature three samples of each category were tested using the percentage mass variation to estimate water absorption.

\section{Hardness Measurement}

The superficial hardness Shore D tests were performed in accordance with ASTM D2240-05(2010). A Shore model S1 digital durometer by Instron was used.

\section{RESULTS AND DISCUSSION}

\section{Tensile Tests}

Typical stress vs. strain plots for the WPCs are reported in Figure 1.

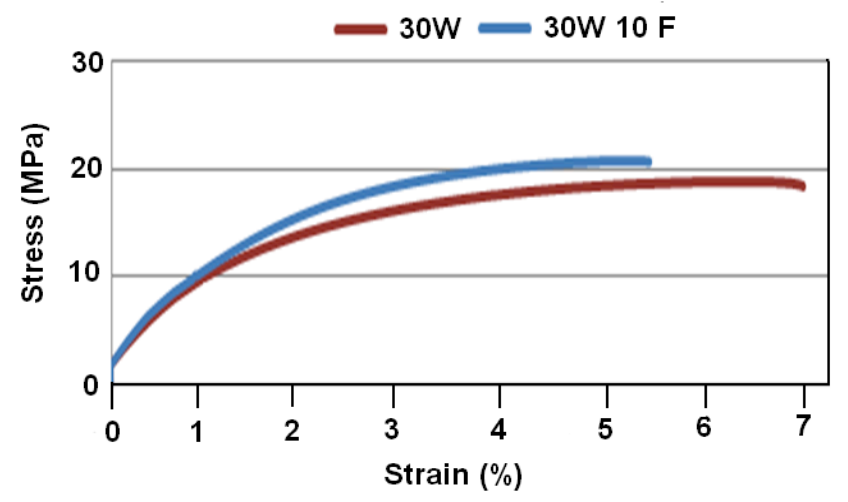


The test shows that the percentage of fibres introduced allows increasing slightly the ultimate load with respect to WPC, while for pure HDPE is slightly higher, and the elastic modulus increases regarding both pure HDPE and WPC. These are hopeful results: we produced samples with hydrophobic matrix and hydrophilic wood flour and cellulosic fibres, the positive results of the tensile test are promising because of the possibility in the future to introduce an additive improving the interface and increasing the ultimate strength. Another way is performing treatments on the fibres before their addition in WPC. The simultaneous presence of fibres and particles moreover is likely allowing reducing the microporosity, the same result will be confirmed from the water absorption test. These numerical results are clearly summarized in table 1 with hardness results.

\section{Scanning Electron Microscopy}

Both the specimens with only wood flour and wood flour added with cellulosic fibres were subjected to SEM analysis. The analysis of the fracture surface of WPC shows a weak interface between the wood fibres and the polymeric matrix: the polyethylene tends to depart from the wood particles because of their different nature. This effect is shown in figure 2 with the mixing homogeneity obtained through turbomixing.

The SEM analysis of WPC added with cellulosic fibres still show a poor interface between the fillers and the matrix as shown in figure 3. Clean wood particles and cellulosic recycled fibres are evident from this picture. A double morphology is also clear and how these two interact themselves.

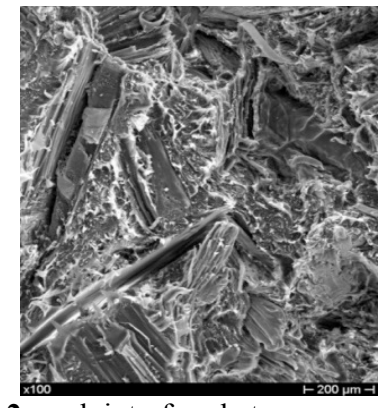

FIGURE 2 weak interface between wood flour (30wt $\%)$ and HDPE matrix, and good dispersion of particles.

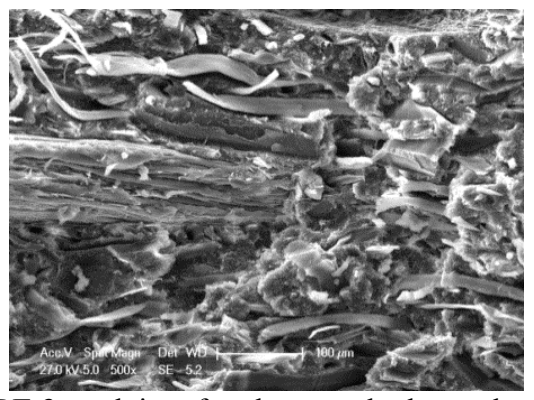

FIGURE 3 weak interface between both wood particle and cellulosic fibres and matrix, and compactness of the matrix.

\section{Water Absorption Tests}

The figures 4-7 show the results of the water absorption tests at different temperature (figures 4-6) and in comparison (figure 7). In all temperature cases a higher mass variation is evident for $30 \mathrm{~W}$ than $30 \mathrm{~W} 10 \mathrm{~F}$. Although the introduction of almost one-third by volume of hydrophilic charge with the fibres add, the composites $30 \mathrm{~W} 10 \mathrm{~F}$ not only don't exceed $30 \mathrm{~W}$ considering absorption but even are characterized by less weight percent mass variation. Cellulosic recycled fibres allow reducing the microporosity: the fibres' presence improve the density of the composite during the mixing process. This effect is more evident than the increased hydrophilic character.

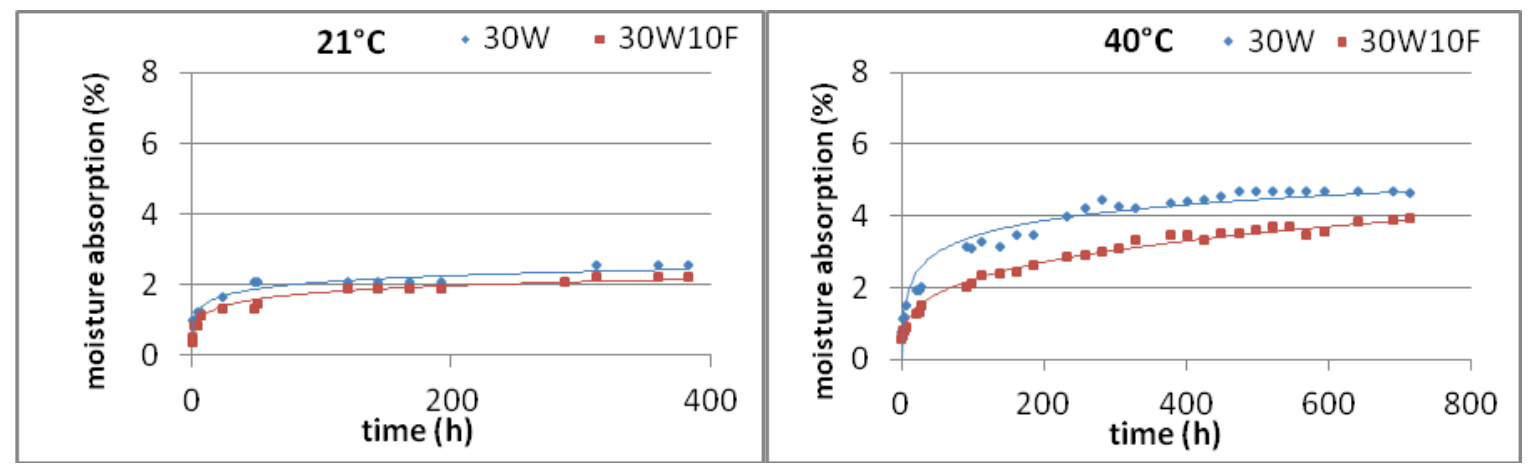


FIGURE 4 Moisture absorption at $21^{\circ} \mathrm{C}$

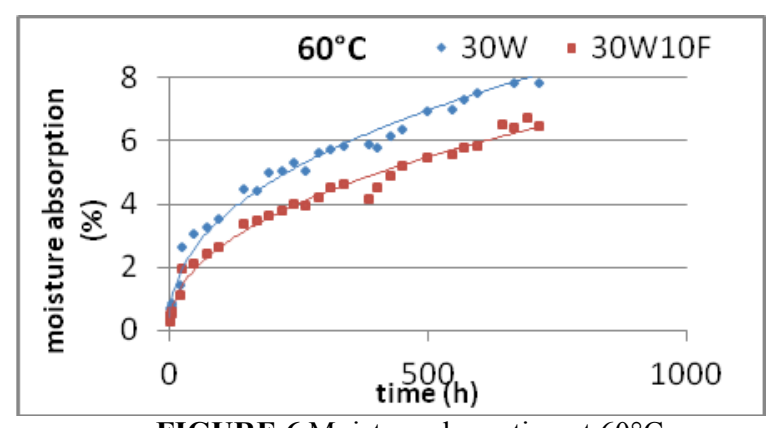

FIGURE 6 Moisture absorption at $60^{\circ} \mathrm{C}$
FIGURE 5 Moisture absorption at $40^{\circ} \mathrm{C}$

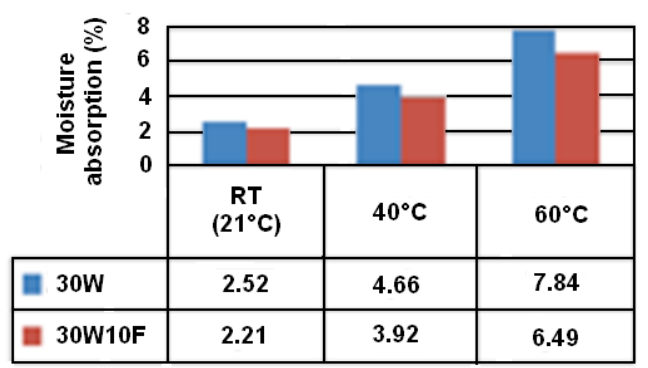

FIGURE 7 Moisture absorption at saturation at 21,40 and $60^{\circ} \mathrm{C}$

\section{Hardness Measurement}

The results of the Shore D tests are summarized in table 1. The presence of cellulosic recycled fibres allows to increase superficial hardness of the composite at all temperature tested (room temperature $\mathrm{RT}, 40^{\circ} \mathrm{C}, 60^{\circ} \mathrm{C}$ ). At high temperature a softening effect is evident: the lowest hardness is recorded at $60^{\circ} \mathrm{C}$ for both family specimens. A lower reduction is recorded for the samples with cellulosic fibres, in accordance with the other obtained results.

TABLE (1) Main results of tensile tests (average values over five specimens with standard deviation) and Shore D hardness (average values over 45 measurements, with three specimens for each family and fifteen measurements for each specimen)

\begin{tabular}{lccccc}
\hline & $\begin{array}{c}\text { Elastic Modulus } \\
(\mathbf{M P a})\end{array}$ & $\begin{array}{c}\text { Ultimate Strength } \\
(\mathbf{M P a})\end{array}$ & $\begin{array}{c}\text { Hardness } \\
\mathbf{R T}\left(\mathbf{2 1}{ }^{\circ} \mathbf{C}\right)\end{array}$ & $\begin{array}{c}\text { Hardness } \\
\mathbf{4 0}^{\circ} \mathbf{C}\end{array}$ & $\begin{array}{c}\text { Hardness } \\
\mathbf{6 0}^{\circ} \mathbf{C}\end{array}$ \\
\hline 30W & $1257(32.01)$ & $18.38(0.86)$ & $48.28(1.37)$ & $47.16(1.09)$ & $43.95(2.98)$ \\
30W10F & $1387(78.05)$ & $19.76(1.06)$ & $52.67(1.80)$ & $49.06(2.11)$ & $46.51(0.84)$ \\
HDPE & $1160(86.6)$ & $21.59(0.18)$ & $52.15(2.45)$ & $44.63(1.5)$ & $40.14(0.53)$ \\
\hline
\end{tabular}

\section{CONCLUSIONS}

Cellulosic recycled fibres were successfully introduced in WPC through turbomixing. Tensile tests offered encouraging results and opened up prospects for future improvements: WPC with cellulosic recycled fibres showed slightly increased elastic modulus and ultimate strength than WPC. The presence of the fibres allowed also reducing the microporosity of the composites. The same result was carried out from the water absorption tests: WPC with cellulosic recycled fibres had a lower mass variation than WPC. The modification of the interface will be desirable, also to increase in the future tensile test results. Both conclusions were confirmed by SEM analysis: the poor interface between dispersed phase and matrix was evident and also the different microporosity of WPC and WPC with cellulosic recycled fibres was clear. The Shore D test showed an increased in superficial hardness for WPC with cellulosic recycled fibres with respect to WPC, another hopeful result to improve WPC properties.

\section{REFERENCES}

1. K. Oksman, N.Sain, M. Sain, Wood-polymer composites, Boca Raton Boston New York Washington, DC, Woodhead publishing limited 2008

2. C. Gozdecki, A. Wilczynske, M. Kociszewski, S. Zajchowski, Properties of wood-plastic composites made of milled particleboard and polypropylene, Eur. J. Wood Prod. (2015) 73:87-95

3. A. Ashori, A. Nourbakhsh, Characeristics of wood-fibre plastic composites made of recycled materials, Waste Management 29 (2009) 1291-1295

4 P. Kuo, S.Y. Wang, J.H. Chen, H.C. Hsueh, M.J. Tsai, Effects of material compositions on the mechanical properties of woodplastic composites manufactured by injection molding, Materials and Design 30 (2009) 3489-3496

5. Valente $\mathrm{M}$ et al. Hybrid recycled glass fibre/wood flour thermoplastic composites: Manufacturing and mechanical characterization. Composites: Part A (2011), doi:10.1016/J.compositesa.2011.02.004

6. M.Valente, J.Tirillò, A.Quitadamo, C.Santulli, "Use of recycled milled-paper in HDPE matrix composites", Proceedings of: $5^{\text {th }}$ International Conference on Innovative Natural Fibre Composites for Industrial Applications, Rome 2015, ISBN 9788890924002 